\title{
POWER OF THE TESTS DENGAN NON-SAMPLE PRIOR INFORMATION PADA PENGUJIAN HIPOTESIS SATU ARAH
}

\author{
Budi Pratikno \\ Jurusan Matematika, Fakultas MIPA, UNSOED Purwokerto \\ bpratikto@gmail.com \\ Lina Sulistia \\ Jurusan Matematika, Fakultas MIPA, UNSOED Purwokerto \\ Yuliatri Wirawidya Haryono \\ Jurusan Matematika, Fakultas MIPA, UNSOED Purwokerto
}

\begin{abstract}
The research discussed power of the tests with non-sample prior information (NSPI) in testing intercept on one-side-hypothesis. The testing is condcuted on a simple regression model (SRM) and multivariate simple regression model (MSRM), and the power of the tests are unrestricted test (UT), restricted test (RT), and preliminary-test test (PTT). The method for choosing the best tests is a maximum power and minimum size. A simulation study and graphical analysis are given using generate and real data. The result showed that the power of the test of the PTT are an alternative choice among the tests on both SRM and MSRM.
\end{abstract}

Keywords: NSPI and powerof the tests of the UT, RT, PTT.

ABSTRAK. Penelitian ini membahas power of the tests dengan non-sample prior information (NSPI) pengujian intersep pada one-side-hypothesis. Pengujian ini dilakukan pada model regresi linier (simple regression model (SRM)) dan model multivariate regresi sederhana (multivariate simple regression model (MSRM)), dengan power of the tests yang digunakan adalah unrestricted test (UT), restricted test $(R T)$, and preliminary-test test (PTT). Metode yang digunakan untuk menetukan uji terbaik adalah maximum power dan minimum size. Simulasi dan analisa grafik diberikan dengan bantuan data riil dan data generate dari $R$ package. Hasil riset menunjukan bahwa PTT merupakan alternatif pilihan yang lebih baik dari UT dan RT untuk kedua model SRM dan MSRM..

Kata Kunci: NSPI dan powerof the tests of the UT, RT, PTT.

\section{PENDAHULUAN}

Penelitian tentang pengujian kesimpulan populasi menggunakan nonsample prior information (NSPI) telah banyak dibahas oleh para peneliti, diantaranya adalah Yunus dan Khan (2011) dan Pratikno (2012) yang menyatakan bahwa kualitas pengujian hipotesis pada kesimpulan populasi dapat ditingkatkan menggunakan non-sample prior information (NSPI). Lebih jauh dengan hal ini, Pratikno telah banyak melakukan riset ini dibeberapa aspek regresi 
model linier dan tipe hipotesis, yaitu two-side hypothesis dan atau one-side hypothesis. Lebih jauh dengan masalah NSPI adalah informasi parameter populasi yang tidak terkait sampel, dan diperoleh dari studi sebelumnya atau pengetahuan para ahli. Bancroft (1944) adalah peneliti pertama yang menggunakan NSPI untuk estimasi parameter. Kemudian dilanjutkan oleh Han dan Bancroft (1968), Judge and Bock (1978), dan Saleh (2006), dan lain-lain. Selanjutnya, Tamura (1965), Saleh dan Sen (1978, 1982), dan Yunus dan Khan (2011), menggunakan NSPI untuk testing hipotesis pada kasus non parametrik. Setelah itu Pratikno (2012) menggunakan NSPI untuk testing hipotesis pada kasus parametrik. Penelitian ini adalah pengembangan penelitian dari Pratikno (2012), yaitu melakukan kajian power of the tests untuk dua model regresi sekaligus pada one-side hipotesis maksimum yang akan membandingkan hasil kesimpulan diantara power of the tests dalam dua model regresi tersebut. Power of the tests yang digunakan dalam pengujian ini adalah unrestricted test (UT), restricted test $(R T)$, and preliminary-test test (PTT), sedangkan model yang menjadi bahasan dalam riset ini adalah simple regression model (SRM) dan multivariate multivariate simple regression model (MSRM).

Penggambaran dan pemahaman testing dengan NSPI pada model regresi, di initiasi dengan penerapan testing ini pada model SRM, yang persamaan umumnya adalah $Y=\beta_{0}+\beta_{1} X+e$, dimana $Y$ adalah response, $\beta_{0}$ adalah parameter intercept, $\beta_{1}$ adalah parameter slope, $X$ adalah predictor, dan $e$ adalah error term yang berdistribusi normal. Estimator untuk $\beta_{0}$ dan $\beta_{1}$ adalah $\hat{\beta}_{0}=\bar{Y}-\hat{\beta}_{1} \bar{X}$ dan

$$
\hat{\beta}_{1}=\frac{\sum_{i=1}^{n} Y_{i} X_{i}-\frac{\left(\sum_{i=1}^{n} Y_{i}\right)\left(\sum_{i=1}^{n} X_{i}\right)}{n}}{\sum_{i=1}^{n} X_{i}^{2}-\frac{\left(\sum_{i=1}^{n} X_{i}\right)^{2}}{n}},
$$

dengan $\bar{Y}=\frac{1}{n} \sum_{i=1}^{n} Y_{i}$ dan $\bar{X}=\frac{1}{n} \sum_{i=1}^{n} X_{i}$ adalah rata-rata dari $Y_{i}$ dan $X_{i}$. Pengujian intercept dengan NSPI melalui UT, RT dan PTT dilakukan untuk menentukan uji 
terbaik, dan ini telah dilakukan dengan simulai data dari generate komputer dari data uniform.

Menurut Pratikno (2012) distribusi yang berlaku pada model SRM adalah distribusi normal (UT, RT) dan bivariate normal distribution (PTT), sedangkan untuk MSRM adalah distribusi sentral $F$ (UT, RT) dan bivariate noncentral $F$ $(P T T)$. Kedua hal tersebut berlaku untuk kedua jenis hipotesis one-side maximum dan minimum. Kriteria yang digunakan adalah investigasi tests yang memiliki nilai power maksimum dan size minimum. Software $R$ digunakan untuk menggambarkan grafik power dan size UT, RT dan PTT.

Pada bagian 2 riset ini dipresentasikan metode penelitian. Hasil dan pembahasan diberikan pada bagian 3. Kesimpulan diberikan di bagian 4 .

\section{METODE PENELITIAN}

Metode penelitian dilakukan dalam tiga tahapan, yaitu (1) melakukan review hasil penelitian terdahulu yang dilakukan Pratikno (2012) tentang grafik power of the tests (UT, RT, PTT) pada testing intercept dengan NSPI, (2) melakukan perhitungan dan penggambaran grafik power of the tests (UT, RT, PTT) untuk testing intercept on oneside hypothesis pada SRM dan MSRM dengan pemilihan data (riil dan generate) mendekati modelnya, dan (4) melakukan komparasi hasil pemilihan test terbaik dari kedua model tersebut, dan membandingkanya dengan kajian teori sebelumnya.

\section{HASIL DAN PEMBAHASAN}

\subsection{Simple Regerssion Model}

Pada bagian ini disajikan hasil review penelitian yang telah dilakukan Pratikno (2012) tentang grafik power of the tests (UT, RT, PTT) pada testing intercept on one-side hyphotesis minimum pada SRM. Hasil penelitian terdahulu menunjukan bahwa power PTT adalah pilihan dominan diantara kedua power UT dan RT. Pada kasus tersebut PTT memprotek hasil yang memberikan maksimum power dan minimum size. Hal ini karena RT mempunyai power dan size maksimum sedangkan UT mempunyai minimum power dan size. Kondisi tersebut menyulitkan penarikan kesimpulan yang berbasis maksimum power dan minimum size, sehingga PTT menjadi alternatif pilihan yang memprotek syarat tersebut. UT, RT dan PTT yang berlaku pada kasus SRM adalah sebagai berikut. 
Selanjutnya, dengan mengacu pada Pratikno (2012), power of the tests (UT, RT, PTT) pada SRM adalah sebagai berikut.

\subsubsection{Power and Size of the UT}

Mengacu Pratikno (2012) power UT dengan taraf signifikansi $\alpha_{1}$ pada one-side hypothesis, $H_{0}: \beta_{0}=0$ versus $H_{1}: \beta_{0}<0$ dan $H_{0}: \beta_{0}=0$ versus $H_{1}: \beta_{0}>0$, adalah dinyatakan sebagai

$$
\begin{aligned}
\pi^{U T}(\lambda) & =P\left(Z^{U T}>z_{\alpha_{1}} \mid M_{n}\right) \\
& =P\left(Z_{1}>z_{\alpha_{1}}-\frac{\lambda_{1}}{m_{1}}\right) \\
& =1-\phi\left(z_{\alpha_{1}}-\frac{\lambda_{1}}{m_{1}}\right)
\end{aligned}
$$

dengan $m_{1}=\sigma\left[1+\frac{n \bar{X}^{2}}{S_{x x}}\right]^{1 / 2}, \lambda_{1}$ adalah $\sqrt{n}\left(\beta_{0}-0\right)$ dan $\phi(x)$ adalah cumulative distribution function (cdf) dari distribusi normal standar. Selanjutnya, ukuran uji UT adalah

$$
\begin{aligned}
\alpha^{U T} & =P\left(Z^{U T}>\mathrm{z}_{\alpha_{1}} \mid H_{0}\right) \\
& =1-\phi\left(z_{\alpha_{1}}-\frac{\sqrt{n}\left(\beta_{0}-0\right)}{\left.\sigma \sqrt{\left[1+\frac{n \bar{X}^{2}}{S_{x x}}\right]} \mid H_{0}: \beta_{0}=0\right)}\right. \\
& =1-\phi\left(z_{\alpha_{1}}-\frac{\sqrt{n}\left(\beta_{0}\right)}{m_{1}}\right)=1-\phi\left(z_{\alpha_{1}}\right) .
\end{aligned}
$$

\subsubsection{Power and Size of the RT}

Kuasa dari RT dengan taraf signifikansi $\alpha_{2}$ diberikan sebagai

$$
\pi^{R T}(\lambda)=P\left(Z^{R T}>z_{\alpha_{2}} \mid M_{n}\right)
$$




$$
\begin{gathered}
=P\left(Z_{2}>z_{\alpha_{2}}-\frac{\lambda_{1}+\lambda_{2} \bar{X}}{m_{2}}\right) \\
=1-\phi\left(z_{\alpha_{2}}-\frac{\lambda_{1}+\lambda_{2} \bar{X}}{m_{2}}\right),
\end{gathered}
$$

dimana $\lambda_{2}$ adalah $\sqrt{n}\left(\beta_{1}-\beta_{10}\right) \overline{\mathrm{x}}$. Selanjutnya, ukuran uji dari RT diberikan sebagai

$$
\alpha^{R T}=1-\phi\left(\mathrm{z}_{\alpha_{2}}-\frac{\lambda_{2} \bar{X}}{m_{2}}\right)
$$

dengan $m_{2}=\sigma$.

\subsubsection{Power and Size of the PTT}

Hasil kajiant Pratikno (2012) menyatakan bahwa power of the test PTT dengan taraf signifikansi $\alpha_{3}$ adalah

$$
\begin{aligned}
\pi^{P T T}(\lambda)= & \left(\text { menolak } H_{0}\right) \\
= & P\left(Z^{P T} \leq z_{\alpha_{3}}, Z^{R T}>z_{\alpha_{2}}\right)+\left(Z^{P T}>z_{\alpha_{3}}, Z^{U T}>z_{\alpha_{1}}\right) \\
= & P\left(Z^{P T} \leq z_{\alpha_{3}}\right) P\left(Z^{R T}>z_{\alpha_{2}}\right)+\left(Z^{P T}>z_{\alpha_{3}}, Z^{U T}>z_{\alpha_{1}}\right) \\
= & \phi\left(z_{\alpha_{3}}-\frac{\lambda_{2} \sqrt{S_{x x}}}{\sigma \sqrt{n}}\right)\left(1-\phi\left(z_{\alpha_{2}}-\frac{\lambda_{1}+\lambda_{2} \bar{X}}{\sigma}\right)\right) \\
& \quad+c_{1 \rho}\left(z_{\alpha_{3}}-\frac{\lambda_{2} \sqrt{S_{x x}}}{\sigma \sqrt{n}}, z_{\alpha_{1}}-\frac{\lambda_{1}}{m_{1}}, \rho \neq 0\right)
\end{aligned}
$$

dengan $c_{1 \rho}$ adalah integral dari peluang normal bivariat. Dalam hal ini $c_{1 \rho}$ didefinisikan untuk setiap bilangan riil $k, l$ dan $-1<\rho<1$, dengan $\rho$ adalah koefisien korelasi antara $Z^{U T}$ dan $Z^{P T}$, sebagai

$$
c_{1 \rho}(k, l, \rho)=\frac{1}{2 \pi \sqrt{1-\rho^{2}}} \int_{k}^{\infty} \int_{l}^{\infty} \exp \left[-\frac{1}{2\left(1-\rho^{2}\right)}\left(x^{2}+y^{2}-2 \rho x y\right)\right] d x d y,
$$


dengan $k=z_{\alpha_{3}}-\frac{\lambda_{2} \sqrt{S_{x x}}}{\sigma \sqrt{n}}, l=z_{\alpha_{1}}-\frac{\lambda_{1}}{m_{1}}$. Kemudian ukuran uji PTT menurut Pratikno (2012) diberikan sebagai

$$
\alpha^{P T T}=\phi\left(\mathrm{z}_{\alpha_{3}}\right)\left(1-\phi\left(\mathrm{z}_{\alpha_{2}}-\frac{\lambda_{2} \bar{X}}{\sigma}\right)\right)+c_{1 \rho}\left(\mathrm{z}_{\alpha_{3}}, \mathrm{z}_{\alpha_{1}}, \rho \neq 0\right) .
$$

\subsubsection{A simulation Study}

Simulasi ini menggunakan data bangkitan dari $R$ package. Grafik kuasa (power) dan ukuran (size) uji pada kasus ini dibangkitan dengan $\beta_{0}=-2, \beta_{1}=-3$, dan $X_{i}$ di generate dari distribusi normal dengan rata-rata 3 dan standar deviasi 5 , sedangkan $\varepsilon_{i}$ dibangkitkan dari distribusi normal dengan $\mu=0$ dan $\sigma^{2}=1$. Data tersebut digunakan untuk one-side hipotesis maximum, sedangkan untuk one-side hipotesis minimum data bangkitan dengan koefisen parameter regresis yang positip telah dilakukan pada penelitian yang lalu. Grafik power of the tests ( UT, RT, dan PTT) dengan koefisien korelasi $(\rho) 0,5$ dan nilai $\lambda_{2}$ berbeda dipaparkan pada Gambar 1 .

(i) $\lambda_{2}=-0.5, \rho=0.5$

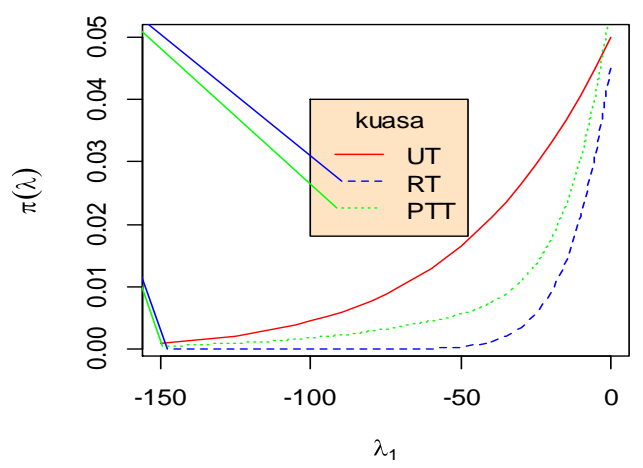

(iv) $\lambda_{2}=-2, \rho=0.5$

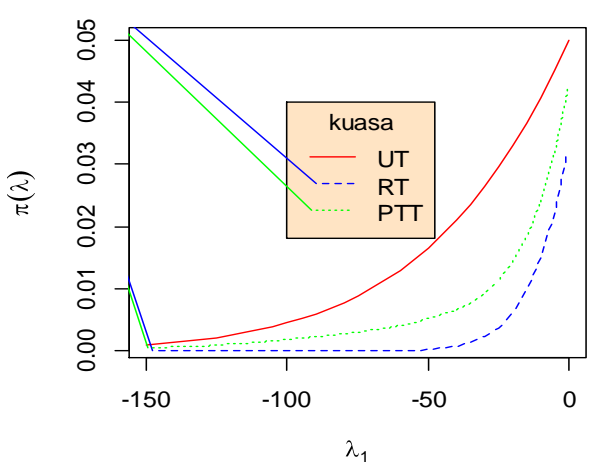

Gambar 1. Power of the tests versus $\lambda_{1}, \lambda_{2}<0$ dan $\rho=0,5$.

Dari Gambar 1, grafik terlihat bahwa power (kuasa) UT tidak berubah, sedangkan RT berubah . Artinya ketika terdapat NSPI pada slope mengakibatkan berubahnya power menjadi menurun. Hal ini juga terjadi pada kuasa PTT 
berubah mengecil. Selain itu, kuasa RT dan PTT selalu lebih kecil dari kuasa UT ketika $\rho=0,5$. Jika korelasi semakin kecil, maka PTT semakin kecil. Selanjutnya, secara analog, grafik size of the tests ( UT, RT, dan PTT) adalah sebagai berikut.
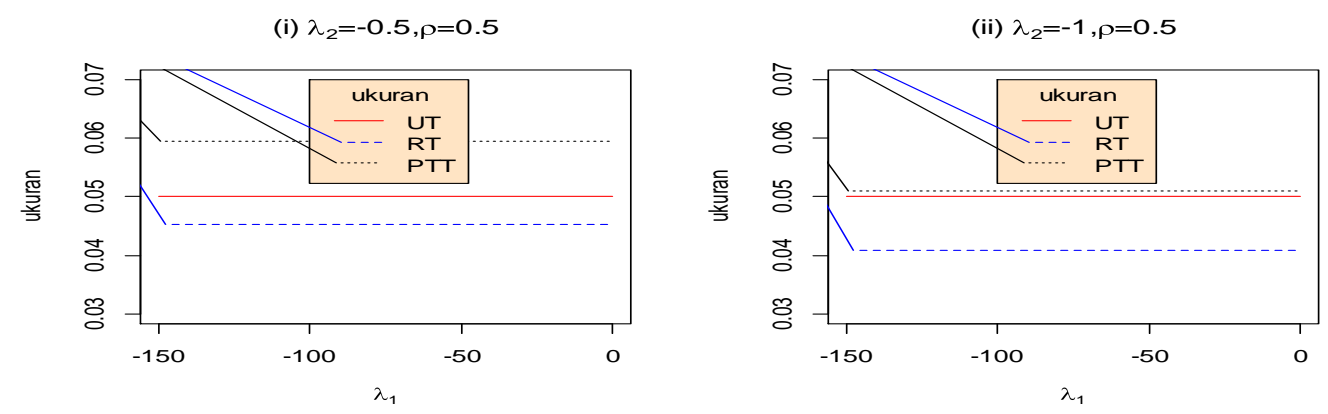

Gambar 2. Size of the tests versus $\lambda_{1}, \lambda_{2}<0$ dan $\rho=0,5$.

Gambar 2 menunjukan bahwa grafik size (ukuran) uji dari PTT lebih besar dari ukuran uji UT dan RT. Ukuran PTT turun sebagaimana nilai $\lambda_{2}$ menurun, Ukuran uji PTT akan meningkat menjadi lebih besar dari ukuran uji RT untuk semua nilai $\lambda_{2}<0$.

\subsection{Multivariate Simple Regerssion Model}

Sejalan dengan SRM, maka pada multivariate simple regression model (MSRM) juga dilakukan review penelitian yang telah dilakukan Pratikno (2012) tentang grafik power of the tests (UT, RT, PTT). Hasil penelitian terdahulu menunjukan bahwa power PTT juga menjadi pilihan dominan diantara kedua power UT dan RT. Power of the tests UT, RT dan PTT yang berlaku pada kasus MSRM adalah merefer pada penelitian Pratikno (2012), sedangkan pengujian dilakukan pada hipotesis one-side hipotesis, sehingga power of the tests UT, RT dan PTT adalah sebagai berikut.

\section{Power of the test UT}

$$
\begin{aligned}
\pi^{U T}(\lambda) & =P\left(T^{U T}>F_{\alpha_{1}, p, n-p} \mid L_{n}\right) \\
& =1-P\left(T_{1}^{U T} \leq F_{\alpha_{1}, p, n-p}-n\left(\beta_{0}-0\right)^{\prime} \Sigma^{-1}\left(\beta_{0}-0\right)\right) \\
& =1-P\left(T_{1}^{U T} \leq F_{\alpha_{1}, p, n-p}-\lambda_{1}^{\prime} \Sigma^{-1} \lambda_{1}\right) \\
& =1-P\left(T_{1}^{U T} \leq F_{\alpha_{1}, p, n-p}-\phi_{1}\right)
\end{aligned}
$$


dengan statistik uji UT berdistribusi $F$ dengan derajat bebas $(p, n-p)$, yaitu

$$
\begin{aligned}
T^{U T} & =\sum_{i=1}^{n}\left(x_{i}-\bar{x}\right)^{2}\left[\left(\tilde{\beta}_{0}-0\right) \Sigma^{-1}\left(\widetilde{\beta}_{0}-0\right)\right] \\
& =\sum_{i=1}^{n}\left(x_{i}-\bar{x}\right)^{2}\left[\tilde{\beta}_{0} \Sigma^{-1} \tilde{\beta}_{0}\right],
\end{aligned}
$$

$L_{n}:\left(\beta_{0}-0, \beta_{1}-\beta_{10}\right)=\left(\frac{\lambda_{1}}{\sqrt{n}}, \frac{\lambda_{1}}{\sqrt{n}}\right)=\lambda$ sebagai rangkaian hipotesisalternatif,

$T_{1}^{U T}=T^{U T}-n \beta_{0}^{\prime} \Sigma^{-1} \beta_{0}$, dan

$$
\begin{aligned}
\Sigma & =\frac{1}{n-p} \sum_{i=1}^{n}\left(Y_{i}-\hat{Y}\right)\left(Y_{i}-\hat{Y}\right)^{\prime} \\
& =\frac{1}{n-p} \sum_{i=1}^{n}\left(Y_{i}-\hat{\beta}_{0}-\hat{\beta}_{1} \bar{x}\right)\left(Y_{i}-\hat{\beta}_{0}-\hat{\beta}_{1} \bar{x}\right)^{\prime} .
\end{aligned}
$$

\section{Power of the test RT}

$$
\begin{aligned}
\pi^{R T}(\lambda) & =P\left(T^{R T}>F_{\alpha_{2}, p, n-p} \mid L_{n}\right) \\
& =P\left(T_{2}^{R T}>F_{\alpha_{2}, p, n-p}-q_{1 r t}\right) \\
& =P\left(T_{2}^{R T}>F_{\alpha_{2}, p, n-p}-n\left[\left(\beta_{0}-0\right)+\left(\beta_{1}-\beta_{10}\right) \bar{x}\right] \Sigma^{-1}\left[\left(\beta_{0}-0\right)+\left(\beta_{1}-\beta_{10}\right) \bar{x}\right]\right) \\
& =1-P\left(T_{2}^{R T} \leq F_{\alpha_{2}, p, n-p}-\left[\lambda_{1}+\lambda_{2} \bar{x}\right] \Sigma^{-1}\left[\lambda_{1}+\lambda_{2} \bar{x}\right]\right) \\
& =1-P\left(T_{2}^{R T} \leq F_{\alpha_{2}, p, n-p}-\left[\lambda_{1}^{\prime} \Sigma^{-1} \lambda_{1}+\lambda_{2}^{\prime} \Sigma^{-1} \lambda_{2} \bar{x}\right]+\lambda_{1}^{\prime} \Sigma^{-1} \lambda_{2} \bar{x}+\lambda_{2}^{\prime} \Sigma^{-1} \lambda_{1} \bar{x}\right) \\
& =1-P\left(T_{2}^{R T} \leq F_{\alpha_{2}, p, n-p}-\left[\phi_{1}+\phi_{2} \bar{x}\right]+\lambda_{1}^{\prime} \Sigma^{-1} \lambda_{2} \bar{x}+\lambda_{2}^{\prime} \Sigma^{-1} \lambda_{1} \bar{x}\right) \\
& =1-P\left(T_{2}^{R T} \leq F_{\alpha_{2}, p, n-p}-\left[\phi_{1}+\phi_{2} \bar{x}^{2}\right]+\omega_{1} \bar{x}+\omega_{2} \bar{x}\right)
\end{aligned}
$$

Dengan $\omega_{1}$ dan $\omega_{2}$ bergantung pada $\lambda_{1}$ maupun $\lambda_{2}$. Statistik uji RT yang berdistribusi $F$ dengan derajat bebas $(p, n-p)$, yaitu

$$
\begin{aligned}
T^{R T} & =\sum_{i=1}^{n}\left(x_{i}-\bar{x}\right)^{2}\left[\left(\bar{Y}-\beta_{10} \bar{x}-0\right) \Sigma^{-1}\left(\bar{Y}-\beta_{10} \bar{x}-0\right)\right] \\
& =\sum_{i=1}^{n}\left(x_{i}-\bar{x}\right)^{2}\left[\left(\bar{Y}-\beta_{10} \bar{x}\right)^{\prime} \Sigma^{-1}\left(\bar{Y}-\beta_{10} \bar{x}\right)\right],
\end{aligned}
$$

dan

$$
\begin{aligned}
T_{2}^{R T} & =T^{R T}-q_{1 r t} \\
& =T^{R T}-n\left[\left(\beta_{0}-0\right)+\left(\beta_{1}-\beta_{10}\right) \bar{x}\right] \Sigma^{-1}\left[\left(\beta_{0}-0\right)+\left(\beta_{1}-\beta_{10}\right) \bar{x}\right] \\
& =T^{R T}-\left[\lambda_{1}+\lambda_{2} \bar{x}\right] \Sigma^{-1}\left[\lambda_{1}+\lambda_{2} \bar{x}\right] .
\end{aligned}
$$




\section{Power of the test PTT}

$$
\begin{aligned}
\pi^{P T T}(\lambda) & =P\left(T^{P T}<a, T^{R T}>c\right)+P\left(T^{P T} \geq a, T^{U T}>b\right) \\
& =P\left(T^{P T}<a\right) P\left(T^{R T}>c\right)+d_{1 r}(a, b) \\
& =\left[1-P\left(T^{P T}>a\right)\right] P\left(T^{R T}>c\right)+d_{1 r}(a, b),
\end{aligned}
$$

dengan

$$
\begin{aligned}
d_{1 r}(a, b) & =\int_{b}^{\infty} \int_{a}^{\infty} f\left(F^{P T}, F^{U T}\right) d F^{P T} d F^{U T} \\
& =1-\int_{0}^{\infty} \int_{0}^{\infty} f\left(F^{P T}, F^{U T}\right) d F^{P T} d F^{U T}
\end{aligned}
$$

dan

$$
\begin{gathered}
a=F_{\alpha_{3}, p, n-p}-\lambda_{2}^{\prime} \Sigma^{-1} \lambda_{2}=F_{\alpha_{3}, p, n-p}-\phi_{2}, \\
b=F_{\alpha_{1}, p, n-p}-\lambda_{1}^{\prime} \Sigma^{-1} \lambda_{1}=F_{\alpha_{1}, p, n-p}-\phi_{1}, \\
c=F_{\alpha_{2}, n, n-1}-\left[\phi_{1}+\phi_{2} \bar{x}\right]+\omega_{1} \bar{x}+\omega_{2} \bar{x} .
\end{gathered}
$$

Integral $\int_{0}^{b} \int_{0}^{a} f\left(F^{P T}, F^{U T}\right) d F^{P T} d F^{U T}$ dapat dihitung dengan menggunakan cdf (cumulative distribution function)dari distribusi $F$ bivariatnon central.

Secara sama dan mengacu pada Pratikno (2012), size untuk UT (Unrestricted Test), RT (Restricted Test), dan PTT (Pre-Test Test) pada model regresi MSRM adalah sebagai berikut.

\section{Size of the test UT}

$$
\begin{aligned}
\alpha^{U T} & =P\left(T^{U T}>F_{\alpha_{1}, n, n-p} \mid H_{0}: \beta_{0}=0\right) \\
& =1-P\left(T^{U T} \leq F_{\alpha_{1}, n, n-p} \mid H_{0}: \beta_{0}=0\right) \\
& =1-P\left(T_{1}^{U T} \leq F_{\alpha_{1}, n, n-p}\right),
\end{aligned}
$$

Size of the test RT

$$
\begin{aligned}
\alpha^{R T} & =P\left(T^{R T}>F_{\alpha_{2}, n, n-p} \mid H_{0}: \beta_{0}=0\right) \\
& =1-P\left(T^{R T} \leq F_{\alpha_{2}, n, n-p} \mid H_{0}: \beta_{0}=0\right) \\
& =1-P\left(T^{R T} \leq F_{\alpha_{2}, n, n-p}-q_{2 r t}\right) \\
& =1-P\left(T_{2}^{R T} \leq F_{\alpha_{2}, n, n-p}-n\left[\left(\beta_{1}-\beta_{10}\right) \bar{x}\right] \Sigma^{-1}\left[\left(\beta_{1}-\beta_{10}\right) \bar{x}\right]\right) \\
& =1-P\left(T_{2}^{R T} \leq F_{\alpha_{2}, n, n-p}-\left[\lambda_{2} \bar{x}\right] \Sigma^{-1}\left[\lambda_{2} \bar{x}\right]\right) \\
& =1-P\left(T_{2}^{R T} \leq F_{\alpha_{2}, n, n-p}-\phi_{2} \bar{x}^{2}\right),
\end{aligned}
$$


Size of the test PTT

$$
\begin{aligned}
\alpha^{P T T} & =P\left(T^{P T} \leq a\left|H_{0}, T^{R T}>g\right| H_{0}\right)+P\left(T^{P T}>a\left|H_{0}, T^{U T}>h\right| H_{0}\right) \\
& =P\left(T^{P T} \leq a\right) P\left(T^{R T}>g\right)+d_{1 r}(a, h) \\
& =\left[1-P\left(T^{P T} \geq a\right)\right] P\left(T^{R T}>g\right)+d_{1 r}(a, h)
\end{aligned}
$$

dengan $g=F_{\alpha_{2}, p, n-p}-q_{2 r t}=F_{\alpha_{2}, p, n-p}-\theta_{2} \bar{x}^{2}$ dan $h=F_{\alpha_{1}, p, n-p}$.

Dari simualsi dengan model yang di tentukan oleh peneliti untuk dua response dan satu predictor dan koefisien regresi ditentukan nilai, maka perbedaan grafik power akan terlihat pada analisis jenis datanya (generate uniform atau generate normal dan atau data riil). Pada grafik dibawah ini (Gambar 3) data yang digunakan adalah data generate uniform karena data riil sulit memenuhi asumsi MSRM. Grafik tersebut menunjukan sigmoid dan power UT paling kecil sedangkan PTT terlentak antara UT dan RT.

(c) $\theta_{2}=0.0000005, \rho=0.1$

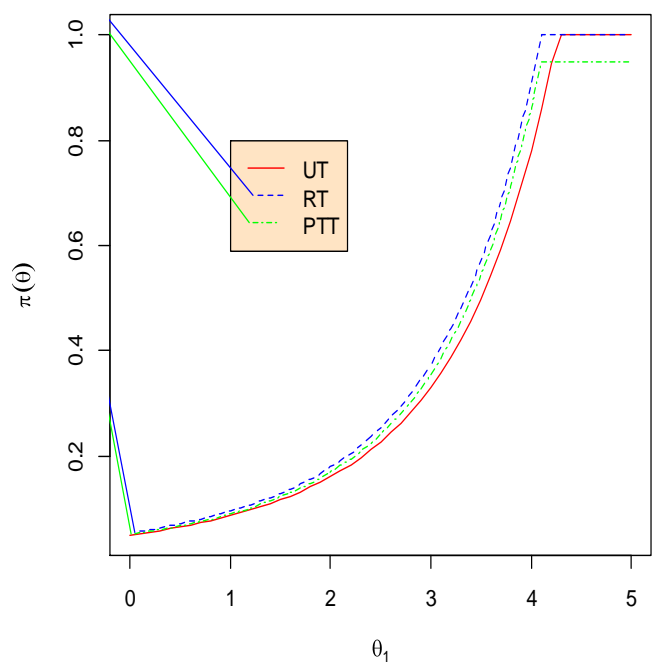

(d) $\theta_{2}=0.0000007, \rho=0.1$

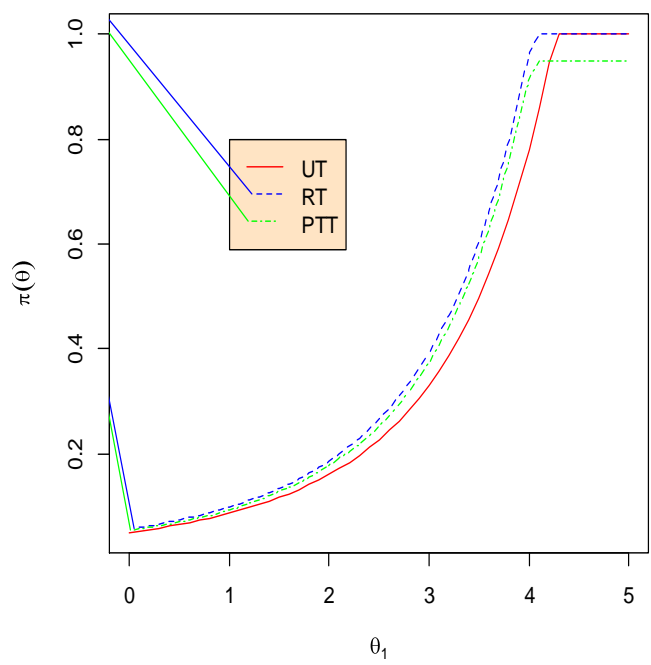

Gambar 3. Grafik kuasa UT, RT, dan PTT dengan $\theta_{2}>0$ dan $\rho=0,1$.

Secara analog bahwa size adalah kasus khusus dari power, yaitu menolah $\mathrm{H}_{0}$ under $\mathrm{H}_{0}$, maka grafik size diberikan pada Gambar 4. 
(a) $\theta_{2}=-5, \rho=0.1$

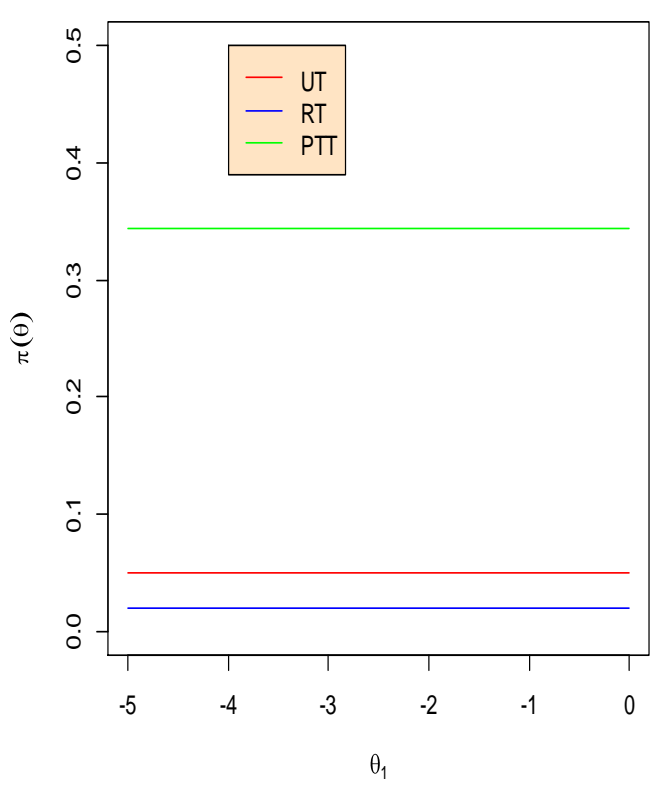

(b) $\theta_{2}=1.5$

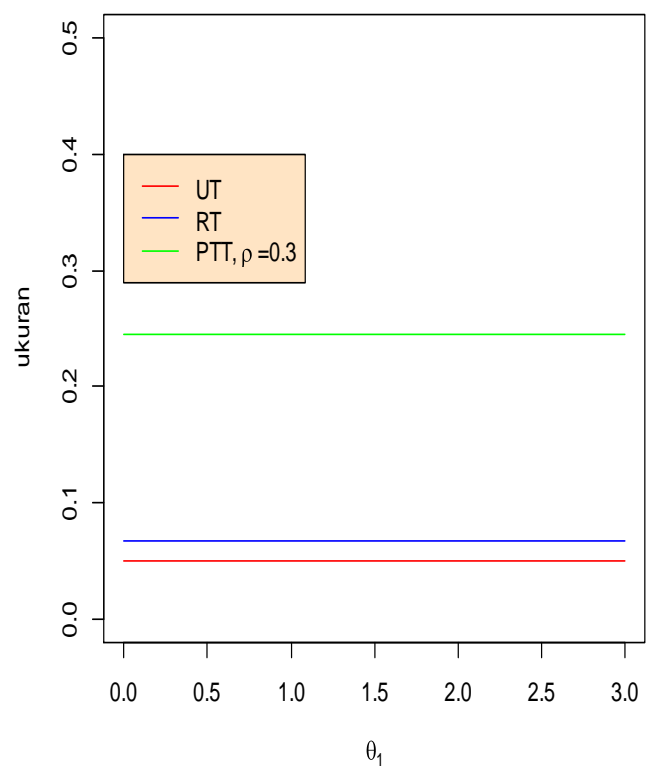

Gambar 4. Grafik size (ukuran) UT, RT, dan PTT dengan $\theta_{2}=-5$ dan $\theta_{2}=1.5$

Gambar 4 menunjukan bahwa size PTT maksimum dan RT minimum. Sedangkan pada kondisi $\theta_{2}>0$ secara jelas menunjukan bahwa size PTT maksimum dan UT minimum. Karena nilai size kecil, maka PTT masih mungkin memberikan pilihan yang menarik walaupun pilihan RT juga bisa menjadi significant.

Analisis grafik berikutnya adalah pada data riil, tetapi karena data sulit memenuhi asumsinya, maka dilakukan transformasi data melalui standarisasi yaitu standarisasi variabel dengan transformasi data pada variabel prediktor, dengan $z=\frac{x-\bar{x}}{s}$, sehingga model yang didapat adalah $y_{1}=96.2171+2.1108 x$, $y_{2}=97.1429+0.8106 x$, dan $y_{3}=4.04571-0.07934 x$. Berikut merupakan grafik power dan size dengan transformasi data riil dengan nilai $\beta_{i i}$ diketahui. 

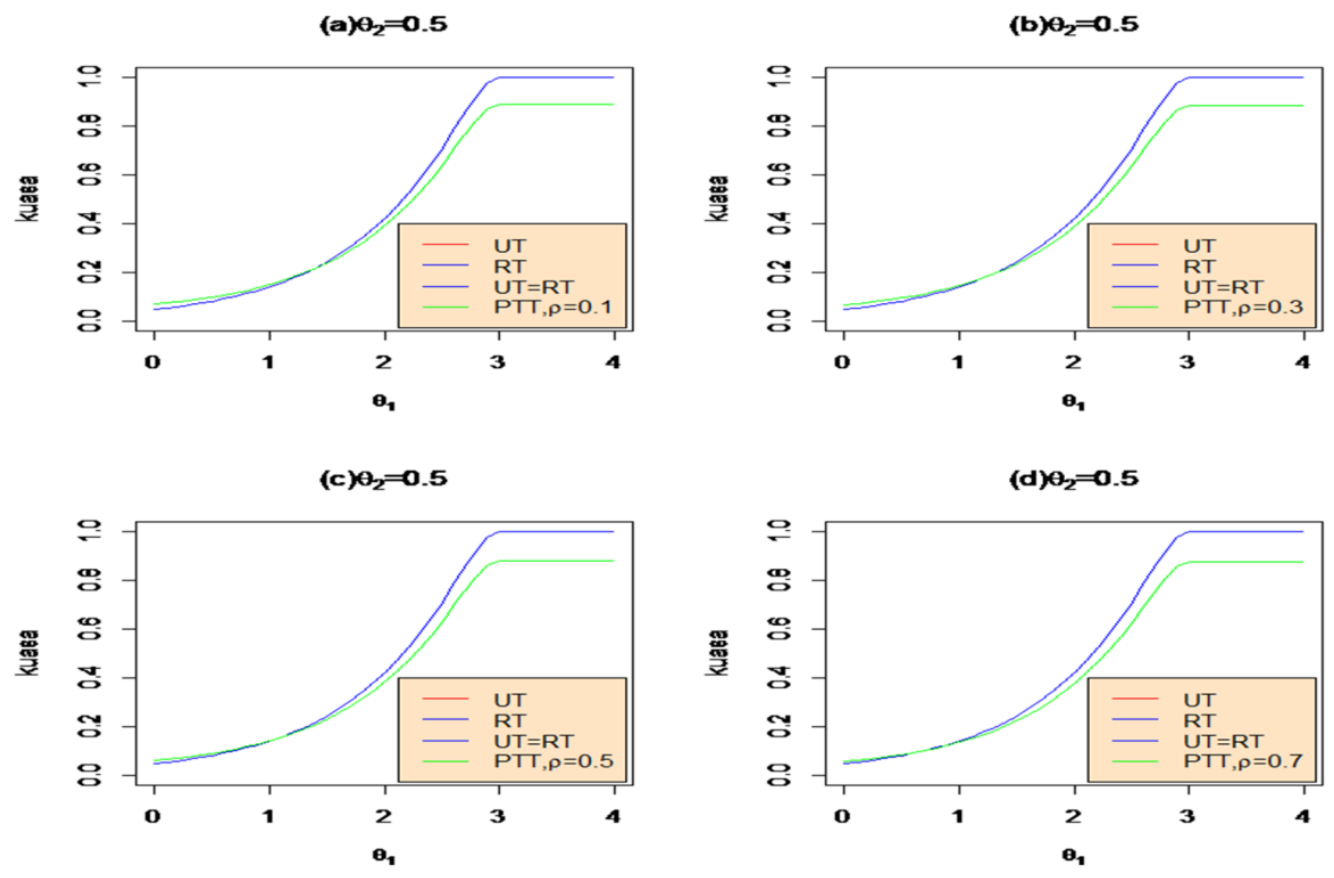

Gambar 5. Grafik Kuasa UT, RT, dan PTT Transformasi Data Riil dengan $\rho=0.1,0.3$, 0.5, 0.7, $\theta_{2}=0.5$, dan $L=11$ pada Nilai $\beta_{i i}$ Diketahui.
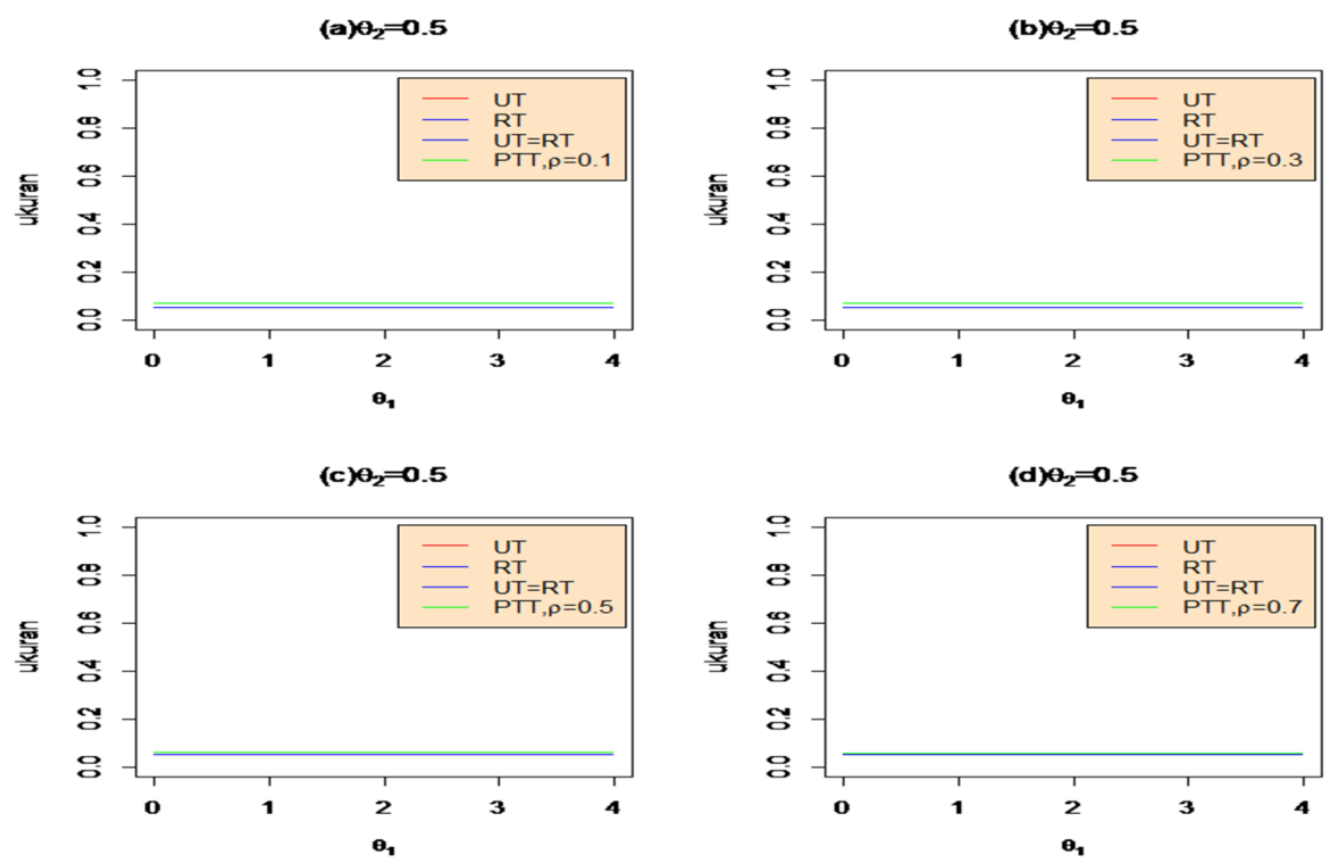

Gambar 6. Grafik Ukuran UT, RT, dan PTT Transformasi Data Riil dengan $\rho=0.1$, $0.3,0.5,0.7, \theta_{2}=0.5$, dan $L=11$ pada Nilai $\beta_{i i}$ Diketahui. 
Gambar 5 dan 6 diatas merupakan grafik power and size dengan mentransformasikan data riil pada variabel prediktor dengan nilai $\beta_{i i}$ diketahui, dan terlihat bahwa grafik diatas sudah mendekati dengan konsep Pratikno (2012). Tetapi untuk nilai UT dan RT masih tampak konstan yaitu grafik yang berwarna biru. Selanjutnya dilakukan penggambaran grafik dengan menggunakan transformasi data riil dengan nilai $\beta_{i i}$ ditentukan.

\section{KESIMPULAN}

Berdasarkan hal tersebut diatas, nilai power of the tests (UT, RT, dan PTT) pada SRM relatif kecil apabila dibandingkan dengan penelitian sebelumnya. Pada kondisi ini UT dan PTT masih bisa menjadi pilihan, sedangkan RT sulit dipertimbangkan. Hal ini ditunjukkan dengan power dan size uji UT yang cenderung maksimum, PTT yang masih berada diantara UT dan RT, dan RT mempunyai minimum power dan size.

Pada MSRM power RT minimum, sedangkan power PTT maksimum, dan UT cenderung diantara keduanya. Lebih jauh bahwa pada kondisi ini menunjukan bahwa size PTT maksimum dan RT minimum, sehingga PTT masih mungkin memberikan pilihan yang menarik walaupun pilihan RT juga bisa menjadi significant. Sedangkan pada aplikasi dengan data riil nilai power of the PTT cenderung relatif lebih kecil dari RT, maka perlu analisa lebih detil untuk mempertimbangakan penyimpulan PTT sebagai test yang dipertimbangkan.

Dari keduanya, maka dapat disimpulkan bahwa karena kecilnya nilai power, maka adanya NSPI dalam slope sangat mempengaruhi nilai power yang menjadikan berdampak pada proses pengambilan kesimpulan ini. Secara umum, hasil dari kedua model tersebut (SRM dan MSRM) bahwa PTT masih menjadi pilihan test jika terdapat treatment NSPI.

\section{DAFTAR PUSTAKA}

Bancroft, T. A., On Biases in Estimation Due to The Use of The Preliminary Tests of Significance, Annals Of Mathematical Statistics, 15 (1944), 190-204. 
Han, C.P. dan Bancroft, T.A, On Pooling Means When Variance Is Un-Known, Journal of American Statistical Association, 63 (1968), 1333-1342.

Judge, G. G. and Bock, M. E., The Statistical Implications of Pre-test and Steinrule Estimators in Econometrics, North-Holland, New York, 1978.

Pratikno, B, Tests of Hypotesis for Linear Regression Models with Non Sample Prior Information, Disertasi, University of Southern Queensland, 2012.

Saleh, E, Theory of Preliminary Test and Stein-Type Estimation with Applications. Wiley, New Jersey, 2006.

Saleh, A. K. Md. E. dan Sen, P. K., Nonparametric Estimation of Location Parameter after A Preliminary Test on Regression, Annals of Statistics, 6 (1978), 154-168.

Saleh, A. K. Md. E. dan Sen, P.K, Nonparametric Tests for Location After Parameter a Preliminary Tests on Regression, Communication in Statistics-Theory and Methods, 12(16) (1982), 1855-1872.

Tamura, R., Nonparametric Inferences with A Preliminary Test, Bull. Math. Stat., 11 (1965), 38-61.

Yunus, R.M. dan Khan, S., Increasing Power of The Test Through Pre-Test - A Robust Method, Communications in Statistics - Theory and Method, 40 (2011), 581-597. 